\title{
REVIEW
}

\section{Descending necrotising mediastinitis: two case reports and review of the literature}

\author{
E. Weaver*,\#, X. Nguyen` and M.A. Brooks"
}

\begin{abstract}
Descending necrotising mediastinitis is a rare and serious infection with a high mortality rate, which complicates pharyngeal or odontogenic infection. Early recognition and treatment are essential in order to minimise morbidity. Evaluation with computed tomography is necessary to confirm the diagnosis and facilitate surgical planning. In addition to prompt empirical antiobiotic therapy, surgical intervention is necessary in nearly all cases. Surgical drainage and debridement may be performed through cervicotomy alone, or through combined cervicotomy and thoracotomy, depending upon the extent of disease. Hyperbaric oxygen therapy may play an auxiliary role. We present two recent cases with characteristic imaging findings, and review the relevant literature.
\end{abstract}

KEYWORDS: Computed tomography, mediastinitis

\section{CASE ONE}

A 60-yr-old male presenting with neck swelling, dysphagia and hoarseness had been extubated 2 days previously following a pneumonia. He had a past medical history of laryngeal cancer treated 10 yrs ago with external beam radiation and chemotherapy. On examination he had bilateral diffuse neck erythema, oedema and right-sided induration. Fibre-optic laryngoscopy showed scabbing of the right hypopharynx and erythematous swelling of the false vocal folds, aryepiglottic folds, and epiglottis. Over the course of $12 \mathrm{~h}$, he developed septic shock with a blood pressure of 70/ $30 \mathrm{mmHg}$, heart rate of 135 beats $\cdot \mathrm{min}^{-1}$, and a temperature of $103^{\circ} \mathrm{F}$. He was started empirically on vancomycin and piperacillin/tazobactam. After stabilisation in the intensive care unit (ICU), computed tomography (CT) imaging of the neck and chest was performed. There was a large amount of subcutaneous air tracking into the deep fascial planes of the anterior neck, oedematous laryngeal mucosa, and bilateral loculated fluid collections tracking throughout the anterior neck extending to the superior mediastinum (fig. 1). CT imaging of the chest showed a complex air and fluid collection in the anterior mediastinum extending to the base of the neck (fig. 2). After review of the images, the patient was taken to the operating room for a combined procedure performed by both head and neck surgeons and thoracic surgeons. Bilateral anterior neck dissections were performed, and blunt dissection, irrigation and debridement were carried out to several centimeters below the sternal manubrium. Penrose drains were left in place. Then, left anterior thoracotomy with debridement of the anterior mediastinum, left pleural decortication and a pericardial window were performed by the thoracic surgeons. Microbiology of the anterior mediastinal fluid grew multiple organisms including Fusobacterium, Prevotella, Bacteroides fragilis, Peptostreptococcus, and a heavy growth of Streptococcus intermedius. Pathology of the pharyngeal lesions showed necrosis and granulation tissue. No neoplasm was identified. The patient later received a tracheostomy and pectoralis myocutaneous flap repair of the neck without sequelae. His total ICU length of stay was 32 days, and his hospital stay was 46 days. Followup CT scans of neck and chest showed improvement in fluid and air collections (fig. 3). He was then transferred to a long-term ventilator care facility.

\section{CASE TWO}

A 37-yr-old male with a history of diabetes presented to the emergency department after a 10-day history of sore throat, neck swelling, and neck erythema. His symptoms progressed despite 5 days of outpatient therapy with cephalexin and steroids. In the emergency department he had a severe cough with purulent sputum and was in respiratory distress with a respiratory rate of

\section{AFFILIATIONS}

*Dept of Medicine, Division of Pulmonary, Critical Care, and Sleep Medicine,

"Dept of Radiology, University of Kentucky, Lexington, KY, and \# Statcare Pulmonary Consultants, Knoxville, TN, USA

CORRESPONDENCE

M.A. Brooks

University of Kentucky

Dept of Radiology

800 Rose St

HX-315C

Lexington

KY 40536-0293

USA

E-mail: mabro03@uky.edu

Received:

Jan 262010

Accepted after revision:

March 102010

PROVENANCE

Submitted article, peer reviewed. 

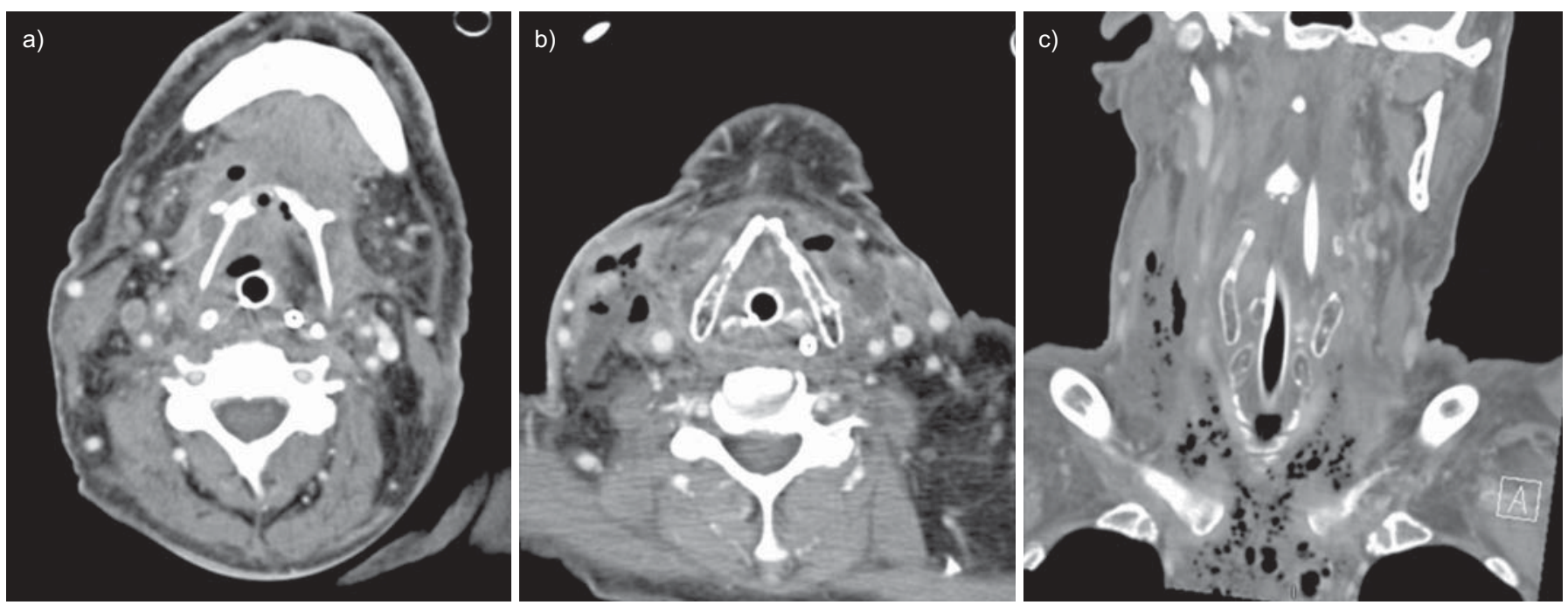

FIGURE 1. Contrast-enhanced computed tomography (CT) of the neck in case one. a) Axial CT image at the level of the hyoid bone demonstrates fluid and gas collections occupying the region of the mylohyoid and strap muscles and the infrahyoid visceral space. b) Axial CT image at the level of the thyroid cartilage shows oedema of the laryngeal mucosa and multiple scattered air and fluid collections in the strap muscles and right sternocleidomastoid, with inflammatory thickening of the skin of the right neck. c) A coronally reformatted image demonstrates the craniocaudal extent of the necrotising process, with numerous gas collections extending into the mediastinum.

38 breaths $\cdot \mathrm{min}^{-1}$ and an arterial haemoglobin saturation of $95 \%$ while breathing $100 \%$ oxygen via a non-rebreather mask. His blood pressure was $165 / 98 \mathrm{mmHg}$ and his heart rate was 122 beats $\cdot \mathrm{min}^{-1}$. On physical examination he had neck swelling, erythema and induration of the left sternocleidomastoid muscle. His laboratory data revealed ketoacidosis and a white blood cell count of $14,000 \mu \mathrm{L}^{-1}$. He was intubated for airway protection and started on cefepime, vancomycin, levofloxacin and clindamycin. Flexible laryngoscopy showed decreased mobility of the left vocal cord but no significant posterior pharyngeal swelling or redness. The initial CT of the neck and chest showed no neck abscess but revealed bilateral pleural effusions, lower lobe airspace disease and mediastinal fluid (fig. 4). He had two chest tubes placed to drain the effusions. Analysis of the pleural fluid showed a white cell count of $8,150 \mu \mathrm{L}^{-1}$, with $96 \%$ neutrophils. Although the fluid showed light growth of Streptococcus intermedius and coagulase-negative Staphylococcus, it was felt

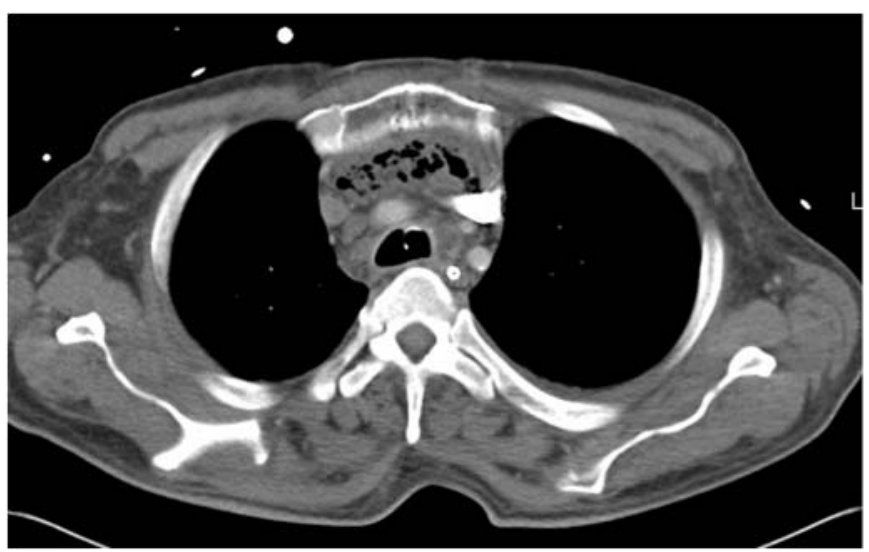

FIGURE 2. Contrast-enhanced chest computed tomography; case one, demonstrating a complex gas and fluid collection in the anterior mediastinum worrisome for mediastinitis. that the infection was probably polymicrobial with anaerobic oral flora. Therefore, broad spectrum antibiotics including cefepime and clindamycin were maintained given the microbiology results. Despite the above therapies, the patient developed worsening fever and sepsis. A repeat CT scan of the neck and chest was performed, which showed extensive fluid collections in the retropharyngeal space, left carotid sheath and posterior triangle of the left neck (fig. 5). The CT of the chest showed fluid collections in the anterior, middle and posterior mediastinum as well as bilateral loculated pleural effusions and a right-sided pneumothorax (fig. 6). The patient was then taken to the operating room, where he underwent anterior neck dissection, which encountered a large amount of pus. This was drained and debrided with blunt dissection, and aggressive irrigation of the posterior triangle and retropharyngeal spaces of the neck was performed. The debrided and irrigated spaces were packed open. After stabilisation in the ICU, the patient was returned to the operating room, where bilateral anterior thoracotomies and bilateral decortication of empyemas was performed. Gross pus was present in the retrosternal region. A large serous pericardial effusion was drained and apericardial window was performed. The patient was managed in the ICU over several weeks. Followup CT scans of the neck and chest showed improvement of fluid and air collections. The patient had a total ICU stay of 36 days and was discharged home on hospital day 51. A follow up CT of the neck and chest 1 month after discharge showed no neck abscess, persistent but improved mediastinal inflammatory changes, and small pleural effusions (fig. 7).

\section{OVERVIEW}

Descending necrotising mediastinitis (DNM) is a rare and very severe infection that may complicate a primary odontogenic or pharyngeal focus. Despite modern therapy, the mortality rate remains high, with reports ranging from $14 \%$ to $50 \%$ [1, 2]. The lethality arises from tissue damage as the infection descends down cervical fascial planes into the mediastinum [3,4]. The term descending necrotising mediastinitis implies the infection 

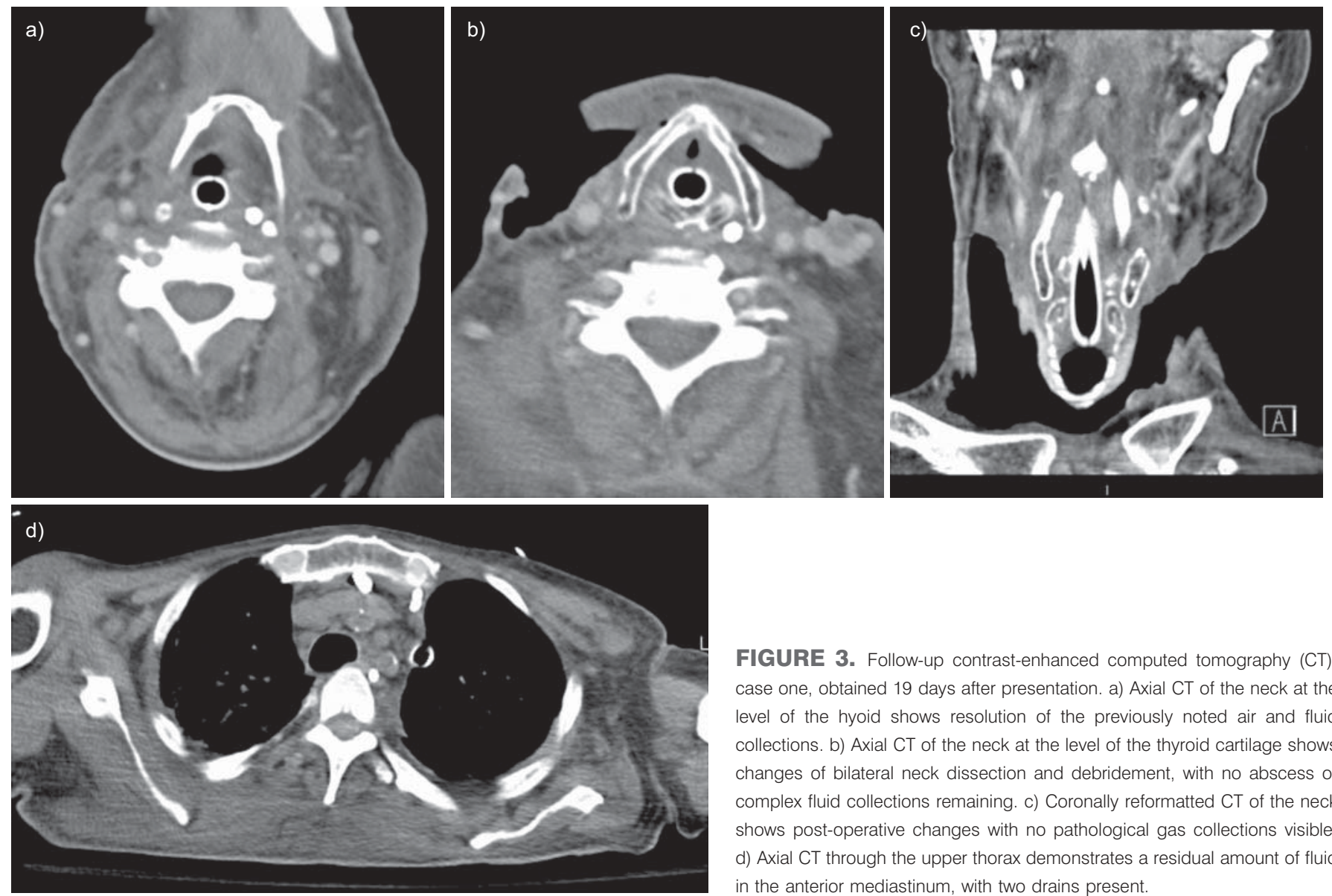

FIGURE 3. Follow-up contrast-enhanced computed tomography (CT); case one, obtained 19 days after presentation. a) Axial CT of the neck at the level of the hyoid shows resolution of the previously noted air and fluid collections. b) Axial CT of the neck at the level of the thyroid cartilage shows changes of bilateral neck dissection and debridement, with no abscess or complex fluid collections remaining. c) Coronally reformatted CT of the neck shows post-operative changes with no pathological gas collections visible. d) Axial CT through the upper thorax demonstrates a residual amount of fluid in the anterior mediastinum, with two drains present.

started from a head and neck source, most commonly an oropharyngeal or odontogenic focus [4-6]. Other reported initial infections that have led to DNM include acute epiglottitis, cervical lymphadenitis, parotitis, thyroiditis, jugular intravenous drug abuse and traumatic endotracheal intubation [7]. The most common origins of DNM infection include peritonsillar, dental or odontogenic abscesses [4]. Odontogenic sources accounted for 58\% of cases of DNM from 1960 to1998 [5].

Case reports and small series documenting the link between odontogenic or pharyngeal focus of initial infection led ESTRERA et al. [8] to develop diagnostic criteria to diagnose DNM in 1983. These criteria include clinical manifestations of severe oropharyngeal infection, demonstration of characteristic imaging features of mediastinitis, documentation of necrotising mediastinal infection at surgery and establishment of a relationship between the oropharyngeal infection and development of a necrotising mediastinal process [8]

Cases of mediastinitis or mediastinal abscess secondary to oesophageal rupture or as complications of cardiothoracic surgery are much more common; however, these forms of mediastinitis are distinctly different from DNM. Localised and encapsulated mediastinal infections may respond to percutaneous or thoracoscopic drainage. In contrast, DNM is a widespread infection of the neck and mediastinum along deep fascial planes that requires aggressive surgical debridement [1, $9,10]$. Several case reports and small case series have examined the optimal diagnostic modalities, antibiotic therapy, role of
CT scanning and surgical approaches [3, 9, 11-18]. Since delay in diagnosis is the primary factor contributing to mortality, the standard of therapy is a comprehensive approach including initial broad spectrum antibiotics, early CT scanning of the neck and thorax, early and wide debridement of cervical and thoracic infection, post-operative ICU monitoring, and surveillance CT scanning and re-operation, as required by clinical course $[2,4]$. Given that optimal surgical treatment usually requires both cervicotomy and thoracotomy or thoracoscopy, as discussed below, cooperative management by both head and neck surgeons and thoracic surgeons is essential.

\section{CLINICAL PRESENTATION AND RISK FACTORS}

Risk factors for DNM include poor dental hygiene, diabetes, i.v. drug abuse, excessive alcohol intake, AIDS and recent steroid use [3]. DNM is also more common in males [19]. Signs and symptoms of the neck infection includes persistent neck pain, fever, neck mass, swelling, trismus, odynophagia, dysphonia, subcutaneous emphysema, skin erythema and decreased oral intake in the setting of tooth abscess, pharyngeal infection, or Ludwig's angina [1, 6]. The diagnosis of DNM can be difficult, owing to the vagueness of the symptoms $[20,21]$. Symptoms of mediastinal infection include chest discomfort, dyspnoea, nonproductive cough or respiratory insufficiency $[3,5,19]$.

\section{CT DIAGNOSIS}

An integral part of the management of DNM is early CT diagnosis [8]. Imaging of cases of suspected DNM can be 

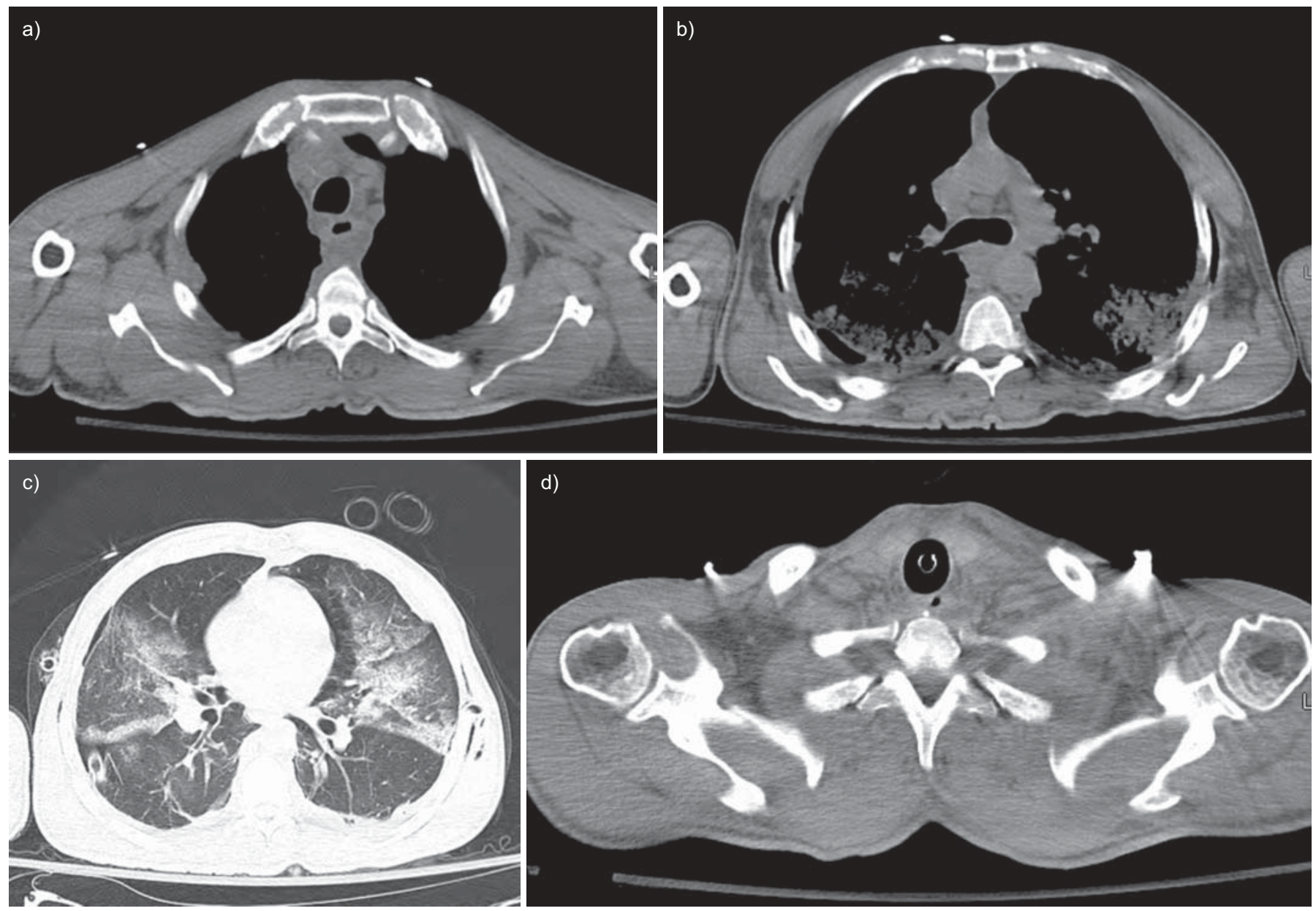

FIGURE 4. Initial non-contrast computed tomography (CT) of the chest and neck; case two. a) Axial CT image through the upper thorax shows fluid collections in the anterior mediastinum and posterior to the oesophagus. b) Axial CT chest image at the level of the carina shows an enlarged pre-carinal lymph node with bilateral air space opacities posteriorly and extrathoracic soft tissue gas along the chest wall. c) Axial CT image through the mid-thorax with lung windows demonstrates bilateral airspace opacities and a small right pneumothorax but no visible mediastinal gas. A chest tube is visible in the right hemithorax. d) Axial CT image through the lower neck shows no cervical abscess or suspicious gas collections.

conceptually divided into two components: assessing soft tissue infection in the neck and determining the presence of mediastinitis. Identification of continuity of an infectious process from the neck into the thorax establishes the diagnosis of DNM [18].

Although conventional radiographs may demonstrate retropharyngeal soft tissue swelling, widening of the superior mediastinal shadow, gas bubbles in the soft tissues of the neck, pneumomediastinum or air-fluid levels in the prevertebral space [4, 22-24], which could in turn prompt further evaluation by $\mathrm{CT}$, radiographic findings are likely to be of limited sensitivity. For instance, a retrospective analysis of a small series of six patients with DNM showed conventional radiographic findings of superior mediastinal widening in only four cases and pneumomediastinum in only three [24].

$\mathrm{CT}$ imaging to visualise soft tissue and potential spaces in the neck and chest is typically obtained $35-60 \mathrm{~s}$ following i.v. administration of an iodine-based contrast medium [6, 25, 26], with contiguous 3 - to 5 -mm sections to include anatomy from the skull base to the dome of the diaphragm. CT evidence of mediastinitis includes localised mediastinal fluid collections or abscesses, gas bubbles in the mediastinal soft tissues, pleural or pericardial effusions, venous thrombosis and lymphadenopathy $[6,22,25]$. Diffuse mediastinitis may be seen, characterised by increased density of the mediastinal fat with resultant loss of definition of normal fat planes [17, 25]. Mediastinal abscess is diagnosed based on the presence of a well-defined low-attenuation fluid collection with or without air, which may demonstrate rim enhancement following contrast administration.

It is important to note that some CT signs suggestive of mediastinitis can be seen in asymptomatic patients up to 21 days following median sternotomy [27, 28]. Thus, correlation between clinical and radiological findings is imperative in these patients. CT findings of mediastinal fluid or air collections have a reported sensitivity of $100 \%$ for detection of post-sternotomy mediastinitis [27], and specificity ranging from $33 \%$ in the immediate post-operative period to $100 \%$ after 15 days post-operative. 

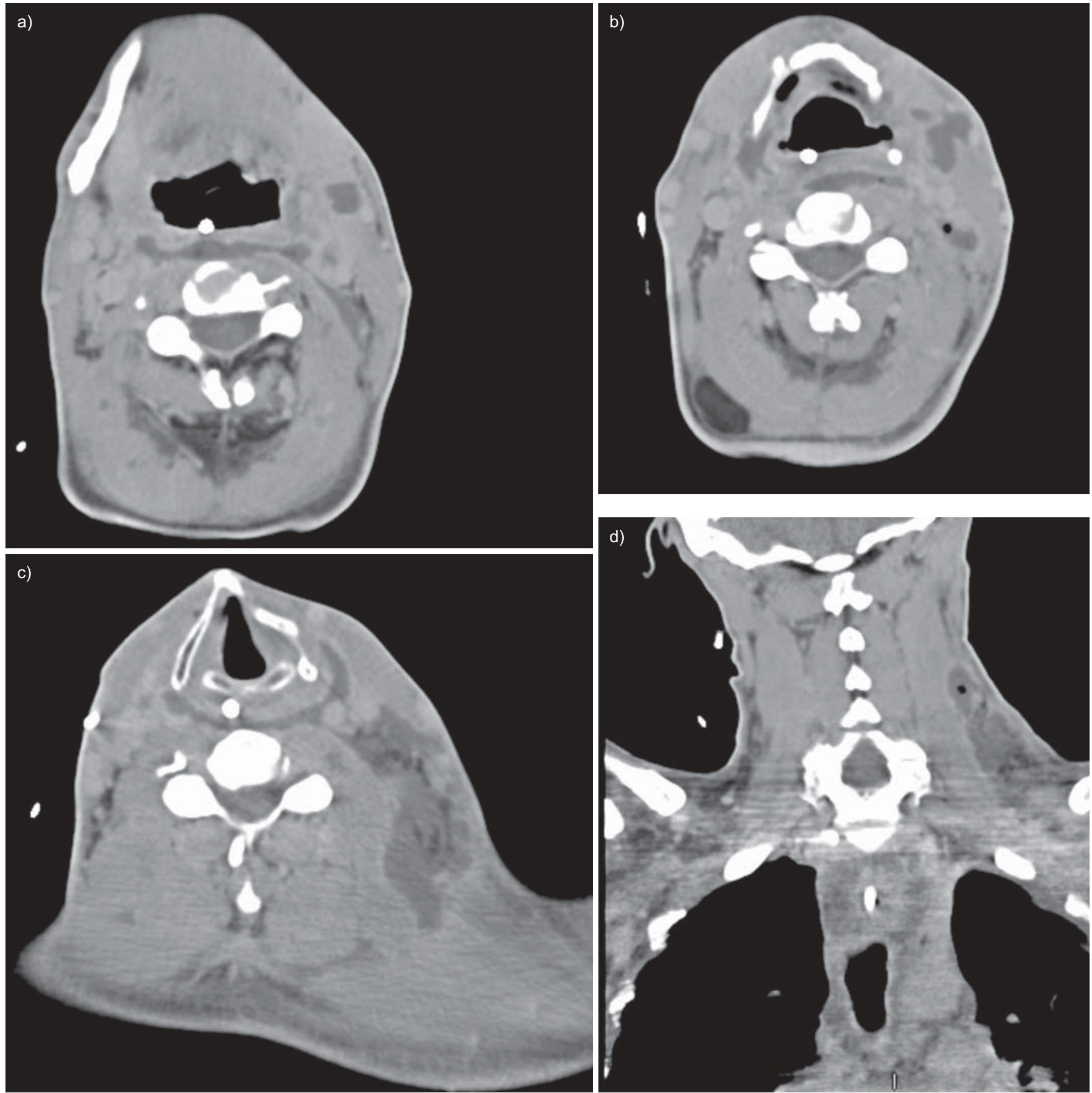

FIGURE 5. Contrast-enhanced computed tomography (CT) images of the neck; case two, 4 days after presentation. a) Axial CT image at the level of the submandibular glands shows fluid attenuation in the retropharyngeal space tracking laterally in the left carotid space. There is also a circumscribed low-density lesion in the left submandibular gland worrisome for abscess. b) Axial CT image at the level of the hyoid demonstrates multiple loculated fluid collections in the left submandibular gland and left carotid space in addition to fluid in the retropharyngeal space. An incidental lipoma is seen at the right posterior neck. c) Axial CT image through the level of the thyroid cartilage shows a complex air and fluid collection extending along the left carotid space into the left posterior cervical space. d) Coronally reformatted CT image demonstrates a fluid and air collection occupying the left posterior triangle.

CT findings in the neck may vary depending on the nature of the infectious focus. Retropharyngeal or odontogenic abscesses may be confirmed on CT. Cervical CT findings supporting infection include cellulitis, myositis, jugular venous thrombosis, lymphadenopathy and abnormal fluid collections [6, 26]. CT may also assist in diagnosing or excluding necrotising fasciitis. Thickening or enhancement of the sternocleidomastoid muscle and the presence of fluid collections in multiple anatomic compartments of the neck are sensitive features of cervical necrotising fasciitis, demonstrated in all patients in one retrospective analysis of 14 surgically proven cases of necrotising fasciitis of the head and neck [26]. 

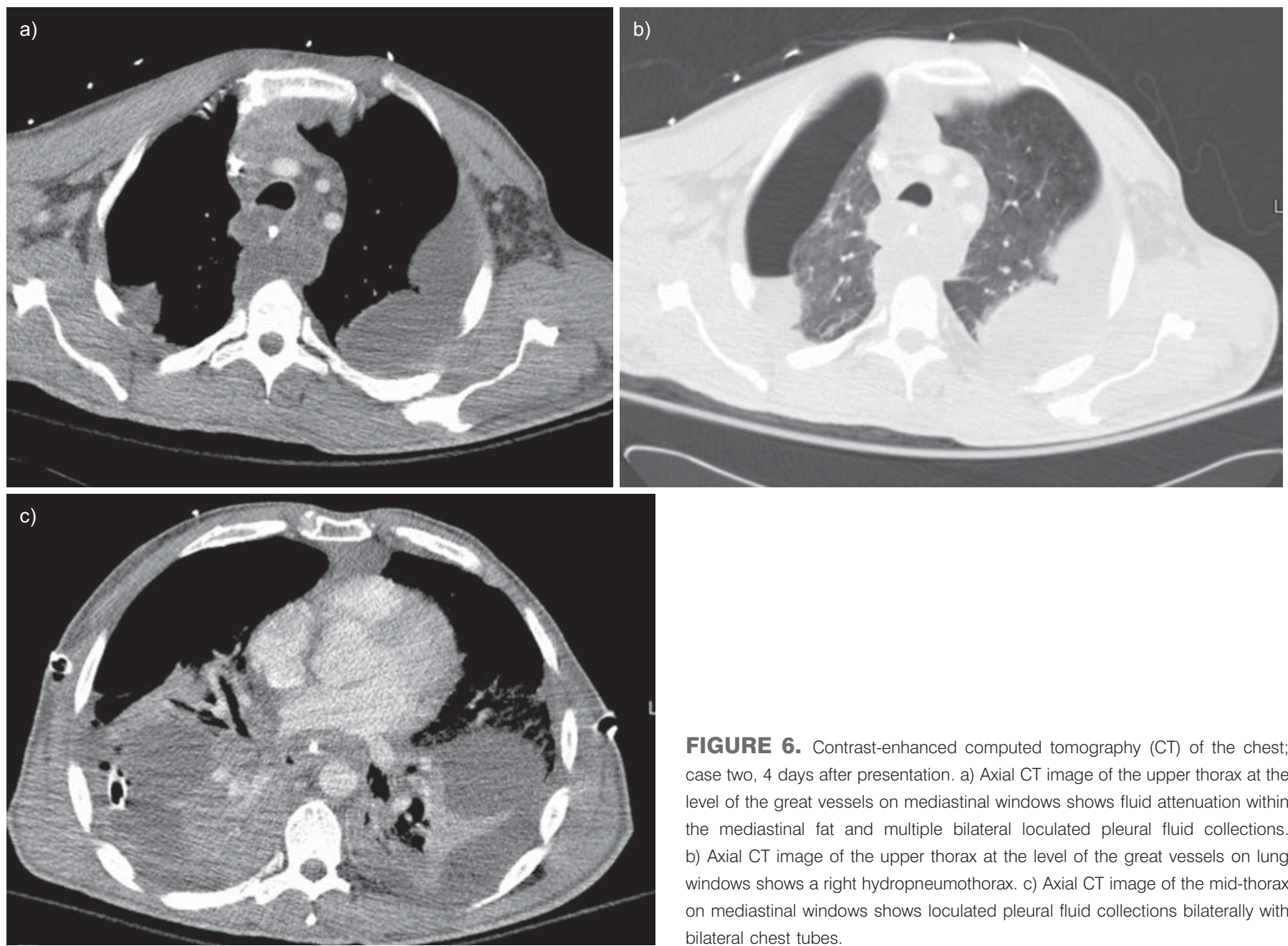

FIGURE 6. Contrast-enhanced computed tomography (CT) of the chest; case two, 4 days after presentation. a) Axial CT image of the upper thorax at the level of the great vessels on mediastinal windows shows fluid attenuation within the mediastinal fat and multiple bilateral loculated pleural fluid collections. b) Axial CT image of the upper thorax at the level of the great vessels on lung windows shows a right hydropneumothorax. c) Axial CT image of the mid-thorax on mediastinal windows shows loculated pleural fluid collections bilaterally with bilateral chest tubes.

In one case series of 34 patients with suspected DNM [6], the absence of suspicious CT signs of infection in the neck or chest spaces excludes DNM with a sensitivity of $100 \%$ based on prediction of a benign non-operative clinical course. However, absence of intrathoracic infection by CT does not necessarily ensure a favourable prognosis if concomitant neck infection is present, as two out of 12 patients without initial evidence of intrathoracic infection in the same study ultimately died from subsequent mediastinal spread when conservatively managed with cervical drainage and antibiotics alone [6].

In addition to confirming a diagnosis of DNM and detecting complications, CT assessment of the extent of infection would aid in determining optimal management [29] and can assist in surgical planning and in assessing response to therapy [30]. In one series, a majority of follow-up CT examinations in DNM patients revealed unanticipated evidence of progression of disease requiring further intervention [30].

\section{ANATOMY, CLASSIFICATION AND SURGICAL TREATMENT}

Knowledge of neck anatomy is essential for planning surgical approaches in DNM, and several detailed reviews of the relevant anatomy are available [2, 22, 31, 32].
The pretracheal space is located anterior to the trachea and posterior to the pretracheal fascia. The inferior border of this space is the pericardium and parietal pleura at the level of the carina, and infections in this space can lead to suppurative pericarditis and empyema $[5,10]$.

The perivascular space is enveloped by the carotid sheath and contains the internal jugular vein, carotid artery, and vagus nerve [5]. All three layers of the deep cervical fascia contribute to the carotid sheath, which descends into the chest, yielding a potential path for descending necrotising infection into the mediastinum and pleural spaces that was nicknamed "Lincoln's Highway" by H.P. Mosher in 1929 [10, 33].

The prevertebral division of the deep layer of the deep cervical fascia extends from the skull base to the coccyx and lies just anterior to the vertebral bodies, tightly apposed to the spine and paraspinous muscles [22, 34]. Two compartments of the prevertebral space of the neck, if infected, can give rise to posterior mediastinitis [6, 21]. The more anterior of these compartments is the retropharyngeal space [4, 22], which is a common route of spread of DNM infection into the posterior mediastinum [10]. The more posterior compartment is known as the "danger space" $[2,22]$. As the danger space extends from the skull base to the diaphragm [22], its clinical significance stems 

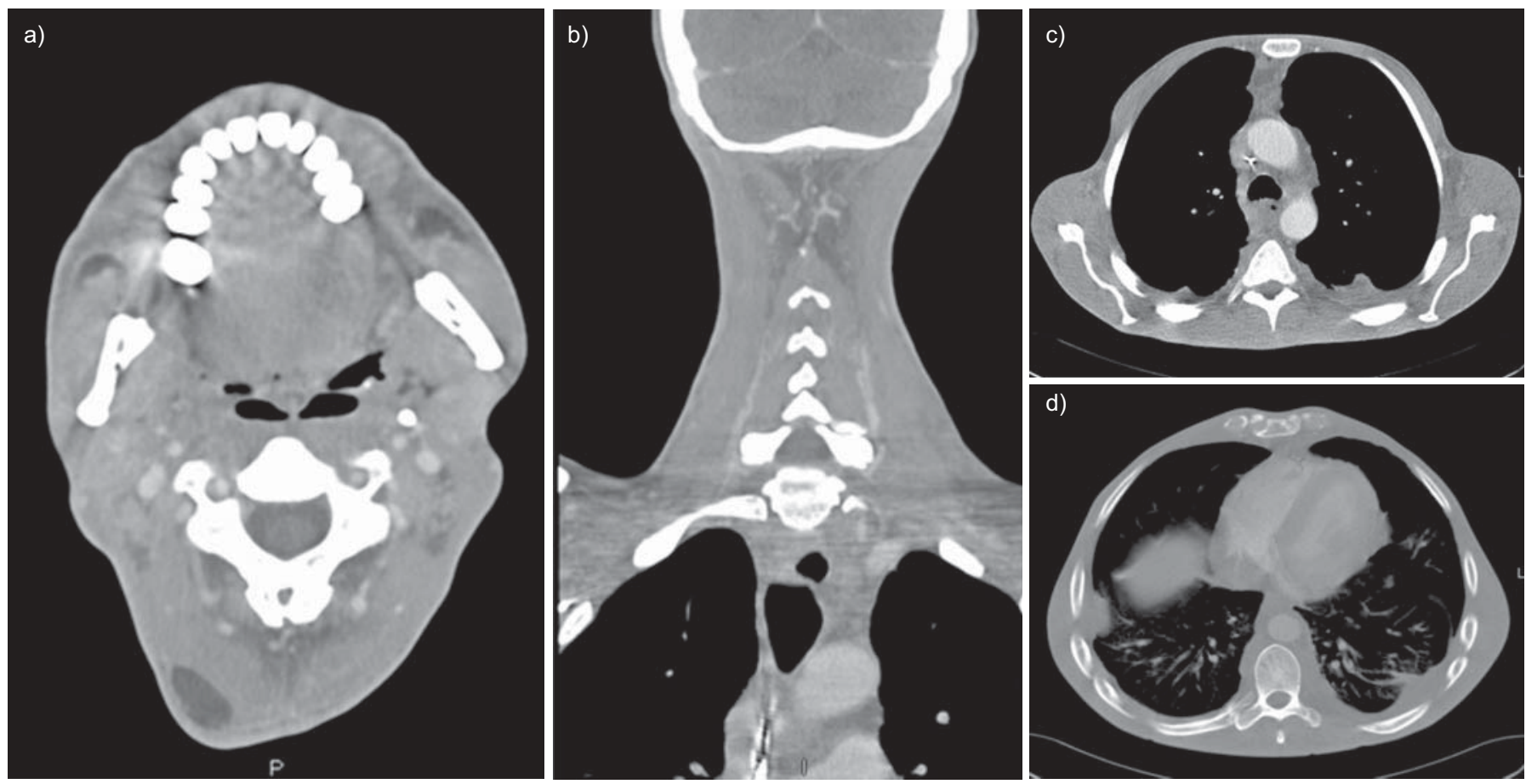

FIGURE 7. Follow-up contrast-enhanced computed tomography (CT) of the neck and chest; case two, 1 month following hospital discharge. a) Axial CT image of the neck at the level of the valleculae shows resolution of previously identified fluid collections. The lipoma at the posterior right neck is again seen. b) Coronally reformatted CT image of the posterior neck shows normal appearance of the posterior triangle. c) Axial CT image of the thorax at the level of the ascending aorta on mediastinal windows shows persistent abnormal inflammatory attenuation in the anterior mediastinum, with small persistent loculated pleural effusions. d) Axial CT image of the mid-thorax using slightly wider windows shows persistent small bilateral pleural effusions.

from the potential for extension of infectious processes from neck into the posterior mediastinum and pleural spaces. Danger space infection can result from rupture of a retropharyngeal space abscess through the alar fascia [10, 34, 35].

A striking feature of DNM is its capacity to cross compartments with resultant infection of other neck and mediastinal fascial compartments and muscles [3]. It is speculated that the downward spread is facilitated by gravity, breathing and negative intrathoracic pressure [5,36], though such hypotheses are difficult to test directly. Some potential explanations for the rapid spread of DNM are poorly vascularised anatomic spaces, paucity of cellular immune defences, local tissue hypoxia resulting from multiple small vessel thromboses, anaerobic bacterial enzymes that promote collagen breakdown and disruption of fascia, and extensive soft tissue oedema associated with the infection [3].

In reported cases of DNM, successful surgical management involves a combination of cervical and mediastinal drainage with or without open thoracotomy $[3,4,8,15,21,29,30,36-44]$. ENDO et al. [29] proposed a classification scheme to facilitate management of DNM based on CT assessment of the extent of infection. Type I (or localised) DNM, defined as infection localised to the upper mediastinum above the tracheal bifurcation, may be adequately managed with mediastinal drainage via a transcervical approach without opening the chest cavity [34, 40,45]. Diffuse DNM is subclassified as type IIA if infection involves the lower anterior mediastinum or as type IIB if the anterior and posterior lower mediastinum is involved [29]. In cases of type IIA infection, cervicotomy and a subxiphoid incision or anterior mediastinotomy may provide adequate exposure for debridement [9]. For type IIB infection, there is ample support in the literature for combined cervicotomy and thoracotomy with wide debridement to evacuate all infected and necrotic tissue [1-3, 9, 15, 39, 46] When infection involves the anterior and posterior mediastinum, the mortality rate with cervicotomy alone is significantly worse [2]. In the meta-analysis by CORSTEN et al. [2], patients that received combined cervicotomy and thoracotomy had a mortality of $19 \%$ versus $47 \%$ in patients receiving cervicotomy alone, which was a statistically significant difference. When infection involves both thoracic cavities, bilateral exploration and debridement is required. This has been accomplished with bilateral video-assisted thorascopic surgery (VATS), unilateral posterior thoracotomy with contralateral VATS exploration, or the clamshell procedure [1, 14,47]. Debridement can be accomplished in a one-stage procedure via the clamshell approach, but may not be tolerated in critically ill patients and carries the risk of sternal osteomyelitis and phrenic nerve palsy $[9,15,47]$. Posterolateral thoracotomy is a well-validated approach to treating a posterior mediastinal infection [4, 9], allowing access to all mediastinal spaces, including the pericardial and pleural spaces, and placement of large-bore chest tubes for mediastinal and pleural drainage [9]. MARTY-ANE et al. [9] achieved a relatively low mortality rate of $16.5 \%$ in their series of 12 patients by aggressively utilising thoracotomy. In their series, all patients that underwent both cervicotomy and thoracotomy survived. More recently, less invasive approaches 
successfully employing thoracoscopic or mediastinoscopic drainage have been reported [11, 14, 48-55].

\section{MICROBIOLOGY AND ANTIBIOTIC THERAPY}

A mixture of the aerobic and anaerobic bacteria found in the oral flora are the predominant microorganisms isolated from DNM patients $[4,20,22]$. The most common aerobic bacteria include alpha haemolytic Streptococcus, Staphlococcus aureus and Klebsiella pneumoniae [5]. The most common anaerobic bacteria include Peptostreptococcus, Bacteroides fragilis, Prevotella and Porphyromonas [56]. Other organisms reported include Streptococcus viridans, Serratia marcescens, Enterobacter, Neisseria, Fusobacterium, Pseudomonas aeruginosa, Escherichia coli [3], Stenotrophomonas [15] and Veilonella [1, 7, 9, 20]. Antibiotic therapy should be started immediately and be broad enough to cover Gram-positive cocci, Gram-negative rods and anaerobic bacteria. Empirical treatment regimens include piperacillintazobactam and vancomycin, clindamycin with either ceftriaxone or ceftazidime, or in penicillin-allergic patients, a quinolone plus clindamycin [57]. Once sensitivities are known, therapy can be tailored accordingly.

\section{ROLE OF HYPERBARIC OXYGEN THERAPY}

Based on hypothesised effects of increased oxygen tension on anaerobic microbial growth [58], hyperbaric oxygen therapy has been suggested as a potential treatment for DNM. While several anecdotal cases of DNM with adjunctive hyperbaric oxygen therapy have been reported [59-61], there is a paucity of reliable evidence to support clinical efficacy. Hyperbaric oxygen therapy in the treatment of various necrotising soft tissue infections has been evaluated retrospectively [62], with results ranging from absence of a beneficial effect to improved survival and tissue preservation when used in conjunction with antibiotics and conventional surgical management. Given the relative infrequency of serious complications from hyperbaric oxygen therapy [62], hyperbaric oxygen therapy may represent a potentially useful adjunct to current management, but probably requires more controlled studies in order to establish therapeutic utility.

\section{COMPLICATIONS OF DNM}

Although the surgical approaches described, together with comprehensive critical care management, have improved mortality, complications of DNM can be severe. These include bilateral empyema, purulent pericarditis, pneumonia and acute respiratory distress syndrome [20]. Reported vascular complications include internal jugular and brachiocephalic venous thrombosis and pseudoaneurysm of the carotid artery [63]. A case of suppurative rupture of the proximal vertebral artery, internal jugular vein and subclavian vein has also been reported [64]. Additional sequelae include septic shock, cardiac tamponade from pericarditis, airway obstruction, pleuromediastinal or pleuro-oesophageal fistula, and erosion into major blood vessels [13, 63, 65]. The oesophageal and aortic hiatuses represent potential routes of spread into the peritoneum and retroperitoneum, and a case of trans-hiatal extension of infection into the retroperitoneum has been reported [66].

\section{STATEMENT OF INTEREST}

None declared.

\section{REFERENCES}

1 Sancho LM, Minamoto H, Fernandez A, et al. Descending necrotizing mediastinitis: a retrospective surgical experience. Eur J Cardiothorac Surg 1999; 16: 200-205.

2 Corsten MJ, Shamji FM, Odell PF, et al. Optimal treatment of descending necrotising mediastinitis. Thorax 1997; 52: 702-708.

3 Makeieff M, Gresillon N, Berthet JP, et al. Management of descending necrotizing mediastinitis. Laryngoscope 2004; 114: 772-775.

4 Mihos P, Potaris K, Gakidis I, et al. Management of descending necrotizing mediastinitis. J Oral Maxillofac Surg 2004; 62: 966-972.

5 Kiernan PD, Hernandez A, Byrne WD, et al. Descending cervical mediastinitis. Ann Thorac Surg 1998; 65: 1483-1488.

6 Scaglione M, Pinto A, Romano S, et al. Determining optimum management of descending necrotizing mediastinitis with $\mathrm{CT}$; experience with 32 cases. Emerg Radiol 2005; 11: 275-280.

7 Moncada R, Warpeha R, Pickleman J, et al. Mediastinitis from odontogenic and deep cervical infection. Anatomic pathways of propagation. Chest 1978; 73: 497-500.

8 Estrera AS, Landay MJ, Grisham JM, et al. Descending necrotizing mediastinitis. Surg Gynecol Obstet 1983; 157: 545-552.

9 Marty-Ane $\mathrm{CH}$, Berthet JP, Alric $\mathrm{P}$, et al. Management of descending necrotizing mediastinitis: an aggressive treatment for an aggressive disease. Ann Thorac Surg 1999; 68: 212-217.

10 al-Ebrahim KE. Descending necrotising mediastinitis: a case report and review of the literature. Eur J Cardiothorac Surg 1995; 9: 161-162.

11 Isowa N, Yamada T, Kijima $\mathrm{T}$, et al. Successful thoracoscopic debridement of descending necrotizing mediastinitis. Ann Thorac Surg 2004; 77: 1834-1837.

12 Min HK, Choi YS, Shim YM, et al. Descending necrotizing mediastinitis: a minimally invasive approach using video-assisted thoracoscopic surgery. Ann Thorac Surg 2004; 77: 306-310.

13 Shimizu K, Otani Y, Nakano T, et al. Successful video-assisted mediastinoscopic drainage of descending necrotizing mediastinitis. Ann Thorac Surg 2006; 81: 2279-2281.

14 Watanabe S, Kariatsumari K, Sakasegawa K, et al. A new combined surgical procedure for severe descending necrotizing mediastinitis with bilateral empyema. Thorac Cardiovasc Surg 2002; 50: 308-310.

15 Papalia E, Rena O, Oliaro A, et al. Descending necrotizing mediastinitis: surgical management. Eur J Cardiothorac Surg 2001; 20: 739-742.

16 Novellas S, Kechabtia K, Chevallier P, et al. Descending necrotizing mediastinitis: a rare pathology to keep in mind. Clin Imaging 2005; 29: 138-140.

17 Exarhos DN, Malagari K, Tsatalou EG, et al. Acute mediastinitis: spectrum of computed tomography findings. Eur Radiol 2005; 15: 1569-1574.

18 Scaglione M, Pinto A, Giovine S, et al. CT features of descending necrotizing mediastinitis - a pictorial essay. Emerg Radiol 2007; 14: 77-81.

19 Garatea-Crelgo J, Gay-Escoda C. Mediastinitis from odontogenic infection. Report of three cases and review of the literature. Int $J$ Oral Maxillofac Surg 1991; 20: 65-68.

20 Sandner A, Borgermann J, Kosling S, et al. Descending necrotizing mediastinitis: early detection and radical surgery are crucial. J Oral Maxillofac Surg 2007; 65: 794-800.

21 Misthos P, Katsaragakis S, Kakaris S, et al. Descending necrotizing anterior mediastinitis: analysis of survival and surgical treatment modalities. J Oral Maxillofac Surg 2007; 65: 635-639.

22 Smith JK, Armao DM, Specter BB, et al. Danger space infection: infection of the neck leading to descending necrotizing mediastinitis. Emerg Radiol 1999; 6: 129-132.

23 Duenas J, Garcia-Menor E, Ibarra De La Rosa I, et al. Descending necrotizing mediastinitis in early childhood: favorable outcome after aggressive treatment. Pediatr Crit Care Med 2003; 4: 476-479. 
24 Cai XY, Zhang WJ, Zhang ZY, et al. Cervical infection with descending mediastinitis: a review of six cases. Int J Oral Maxillofac Surg 2006; 35: 1021-1025.

25 Dwivedi MK, Pal RK, Gupta R, et al. CT findings of descending necrotizing mediastinitis. Indian J Radiol Imaging 2001; 11: 131-134.

26 Becker M, Zbaren P, Hermans R, et al. Necrotizing fasciitis of the head and neck: role of CT in diagnosis and management. Radiology 1997; 202: 471-476.

27 Jolles H, Henry DA, Roberson JP, et al. Mediastinitis following median sternotomy: CT findings. Radiology 1996; 201: 463-466.

28 Carrol CL, Jeffrey RB Jr, Federle MP, et al. CT evaluation of mediastinal infections. J Comput Assist Tomogr 1987; 11: 449-454.

29 Endo S, Murayama F, Hasegawa T, et al. Guideline of surgical management based on diffusion of descending necrotizing mediastinitis. Jpn J Thorac Cardiovasc Surg 1999; 47: 14-19.

30 Freeman RK, Vallieres E, Verrier ED, et al. Descending necrotizing mediastinitis: an analysis of the effects of serial surgical debridement on patient mortality. J Thorac Cardiovasc Surg 2000; 119: 260-267.

31 Pearse HE. Mediastinitis following cervical suppuration. Ann Surg 1938; 108: 588-611.

32 Furstenberg AC, Yglesias L. Mediastinitis: a clinical study with practical anatomic considerations of the neck and mediastinum. Arch Otolaryngol 1937; 25: 539-554.

33 Mosher HP. The submaxillary fossa, approach to deep pus in the neck. Trans Am Acad Ophthalmol Otolaryngol 1929; 34: 19-26.

34 Beasley DJ, Amedee RG. Deep neck space infections. J La State Med Soc 1995; 147: 181-184.

35 Watanabe M, Ohshika Y, Aoki T, et al. Empyema and mediastinitis complicating retropharyngeal abscess. Thorax 1994; 49: $1179-1180$.

36 Mitjans MS, Sanchis JB, Padro XB, et al. Descending necrotizing mediastinitis. Int Surg 2000; 85: 331-335.

37 Chen KC, Chen JS, Kuo SW, et al. Descending necrotizing mediastinitis: a 10-year surgical experience in a single institution. J Thorac Cardiovasc Surg 2008; 136: 191-198.

38 Wheatley MJ, Stirling MC, Kirsh MM, et al. Descending necrotizing mediastinitis: transcervical drainage is not enough. Ann Thorac Surg 1990; 49: 780-784.

39 Marty-Ane $\mathrm{CH}$, Alauzen $\mathrm{M}$, Alric $\mathrm{P}$, et al. Descending necrotizing mediastinitis. Advantage of mediastinal drainage with thoracotomy. J Thorac Cardiovasc Surg 1994; 107: 55-61.

40 Brunelli A, Sabbatini A, Catalini G, et al. Descending necrotizing mediastinitis. Surgical drainage and tracheostomy. Arch Otolaryngol Head Neck Surg 1996; 122: 1326-1329.

41 Kim JT, Kim KH, Lee SW, et al. Descending necrotizing mediastinitis: mediastinal drainage with or without thoracotomy. Thorac Cardiovasc Surg 1999; 47: 333-335.

42 Lavini C, Natali P, Morandi U, et al. Descending necrotizing mediastinitis. Diagnosis and surgical treatment. J Cardiovasc Surg (Torino) 2003; 44: 655-660.

43 Iwata $\mathrm{T}$, Sekine $\mathrm{Y}$, Shibuya $\mathrm{K}$, et al. Early open thoracotomy and mediastinopleural irrigation for severe descending necrotizing mediastinitis. Eur J Cardiothorac Surg 2005; 28: 384-388.

44 Roccia F, Pecorari GC, Oliaro A, et al. Ten years of descending necrotizing mediastinitis: management of 23 cases. J Oral Maxillofac Surg 2007; 65: 1716-1724.

45 Brunelli A, Sabbatini A, Catalini G, et al. Descending necrotizing mediastinitis: cervicotomy or thoracotomy? J Thorac Cardiovasc Surg 1996; 111: 485-486
46 Hirai S, Hamanaka Y, Mitsui N, et al. Surgical treatment of virulent descending necrotizing mediastinitis. Ann Thorac Cardiovasc Surg 2004; 10: 34-38

47 Ris HB, Banic A, Furrer M, et al. Descending necrotizing mediastinitis: surgical treatment via clamshell approach. Ann Thorac Surg 1996; 62: 1650-1654.

48 Roberts JR, Smythe WR, Weber RW, et al. Thoracoscopic management of descending necrotizing mediastinitis. Chest 1997; 112: 850-854.

49 Nagayasu T, Akamine S, Oka T, et al. Thoracoscopic drainage with wound edge protector for descending necrotizing mediastinitis. Interact Cardiovasc Thorac Surg 2003; 2: 58-60.

50 Nakamura Y, Matsumura A, Katsura H, et al. Successful videothoracoscopic drainage for descending necrotizing mediastinitis. Gen Thorac Cardiovasc Surg 2009; 57: 111-115.

51 Cho JS, Kim YD, I H, et al. Treatment of mediastinitis using videoassisted thoracoscopic surgery. Eur J Cardiothorac Surg 2008; 34: 520-524.

52 Maki K, Yamamoto S, Ishii $\mathrm{H}$, et al. [Successful treatment for descending necrotizing mediastinitis; report of a case]. Kyobu Geka 2007; 60: 165-167.

53 Son HS, Cho JH, Park SM, et al. Management of descending necrotizing mediastinitis using minimally invasive video-assisted thoracoscopic surgery. Surg Laparosc Endosc Percutan Tech 2006; 16: 379-382.

54 Endo S, Tsubochi H, Nakano T, et al. Descending necrotizing mediastinitis secondary to retropharyngeal abscess without cervical spread. Gen Thorac Cardiovasc Surg 2008; 56: 25-27.

55 Ohno K, Yamasaki Y, Hatanaka N, et al. [Mediastinoscopic drainage for descending necrotizing mediastinitis]. Jpn J Thorac Cardiovasc Surg 1998; 46: 175-178.

56 Brook I, Frazier EH. Microbiology of mediastinitis. Arch Intern Med 1996; 156: 333-336.

57 Cirino LM, Elias FM, Almeida JL. Descending mediastinitis: a review. Sao Paulo Med J 2006; 124: 285-290.

58 Brummelkamp WH. [The importance of administration of oxygen under atmospheric positive pressure in the treatment of gas phlegmon]. Ned Tijdschr Geneeskd 1961; 105: 2430-2432.

59 Kamiyoshihara M, Hamada Y, Ishikawa S, et al. [Hyperbaric oxygen as an adjunctive treatment for descending necrotizing mediastinitis: report of a case]. Kyobu Geka 2000; 53: 715-717.

60 Buczynski K, Gozdziuk K, Wilczynski G, et al. [A rare case of gaseous gangrenous mediastinitis]. Pneumonol Alergol Pol 2003; 71: 95-98.

61 Hang LW, Lien TC, Wang LS, et al. Hyperbaric oxygen as an adjunctive treatment for descending necrotizing mediastinitis: a case report. Zhonghua Yi Xue Za Zhi (Taipei) 1997; 60: 52-56.

62 Jallali N, Withey S, Butler PE. Hyperbaric oxygen as adjuvant therapy in the management of necrotizing fasciitis. Am J Surg 2005; 189: 462-466.

63 Colmenero Ruiz C, Labajo AD, Yanez Vilas I, et al. Thoracic complications of deeply situated serous neck infections. J Craniomaxillofac Surg 1993; 21: 76-81.

64 Hudorovic N, Vucetic B. Infrequent life-threatening complication of descending necrotizing mediastinitis; vertebral artery, internal jugular and subclavian vein rupture. Int J Surg 2008; 6: e48-e51.

65 Kruyt PM, Boonstra A, Fockens P, et al. Descending necrotizing mediastinitis causing pleuroesophageal fistula. Successful treatment by combined transcervical and pleural drainage. Chest 1996; 109: 1404-1407.

66 Vaideeswar P, Tandon SP. Further descent of descending necrotizing mediastinitis. Ann Thorac Surg 1999; 68: 1443. 